Case Report

\title{
Massive Cervicothoracic Subcutaneous Emphysema and Pneumomediastinum Developing during a Dental Hygiene Procedure
}

\author{
Gabriele Bocchialini, Serena Ambrosi, and Andrea Castellani \\ Maxillo-Facial Surgery Unit, Spedali Civili di Brescia, Piazzale Spedali Civili 1, 25123 Brescia, Italy \\ Correspondence should be addressed to Gabriele Bocchialini; gabriele.bocchialini@libero.it
}

Received 1 February 2017; Revised 29 March 2017; Accepted 10 April 2017; Published 13 April 2017

Academic Editor: Gerardo Gómez-Moreno

Copyright (C) 2017 Gabriele Bocchialini et al. This is an open access article distributed under the Creative Commons Attribution License, which permits unrestricted use, distribution, and reproduction in any medium, provided the original work is properly cited.

Subcutaneous emphysema is rare during or after dental procedures (usually extractions). Here, we describe the case of a 65 -yearold woman who developed massive cervicothoracic subcutaneous emphysema and pneumomediastinum during a dental hygiene procedure employing an artificial airflow. She was diagnosed based on clinical manifestations and computed tomography (CT). CT revealed massive subcutaneous emphysema extending from the superior left eyelid to the diaphragm. We describe the clinical and radiological characteristics of this rare case.

\section{Introduction}

A variety of procedures can cause subcutaneous emphysema and pneumomediastinum, including injury, head and neck surgery, mechanical ventilation, and invasive procedures such as bronchoscopy. A few cases have been observed during dental procedures, principally third molar extraction $[1,2]$. Emphysema can also be caused by an increase in mouth air pressure caused by playing a wind instrument [3] or blowing up a balloon [4]. Emphysema developing during or after dental procedures is rare; most cases have been limited to the head and neck, with only a few involving the mediastinum [5].

We present a rare case of a patient diagnosed with massive subcutaneous emphysema extending from the superior left eyelid to the diaphragm. The condition developed during a mandibular dental hygiene procedure in the absence of any visible intraoral incision.

\section{Case Report}

A 65-year-old woman was referred by her dentist to the emergency department of Spedali Civili Brescia, Italy, with a large swelling of the face and the neck that commenced at the upper left eyelid. Pain was not aggravated on palpation, but dysphagia, dyslalia, and subcutaneous crepitus were evident. An intraoral examination revealed no visible incision; slight bleeding was apparent around an implant in the region of 34 . She reported that she had undergone an airflow procedure performed by a dental hygienist in the region of the implant earlier the same day and had felt pain in the left submandibular region during the procedure. She was diagnosed with subcutaneous emphysema (procedural complication).

Her vital signs were as follows: heart rate 65 beats per minute; blood pressure 145/90 mmHg; respiration 19 breaths per minute; and oxygen saturation $96 \%$.

To evaluate the dysphagia and dyslalia, we obtained CT from the maxillofacial region to the thorax. These revealed significant soft-tissue emphysema extending from the left parietal region to the left soft tissue of the face, then bilaterally to the paraspinal muscles of the neck and the pterygoid regions, and posteriorly to the pharynx.

More distally, the emphysema splayed the vascular bundle and the thyroid lobes, widened the pectoral muscles posterior to the clavicles, descended to the mediastinum (where it was evident principally in the anterior part of the perivascular adiposity), and surrounded the trachea and oesophagus posteriorly. 


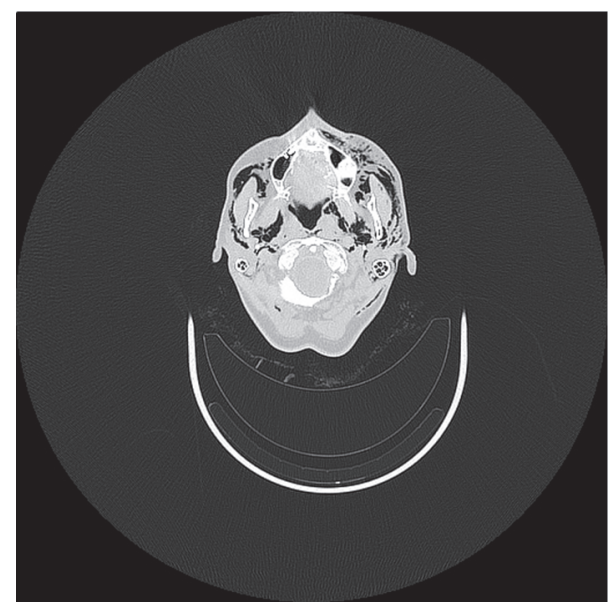

Figure 1: Computed tomographic axial view of the emphysema in the maxillary region.

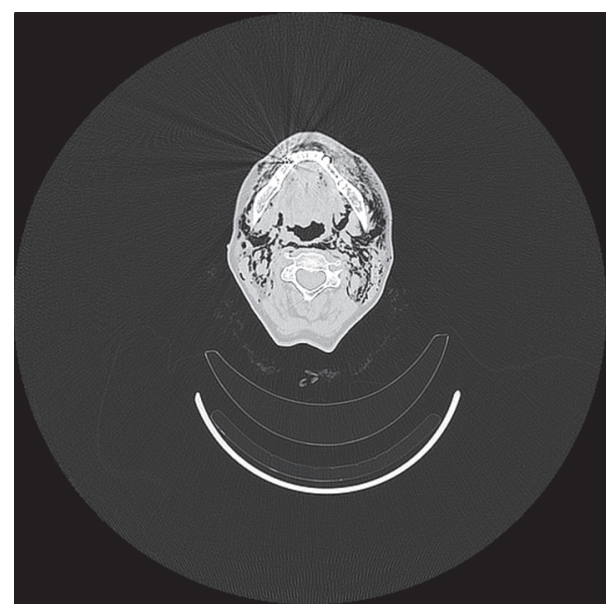

FIGURE 2: Computed tomographic axial view of the emphysema in the mandibular region.

The emphysema terminated in the region of the upper diaphragm (Figures 1-4).

To prevent the expansion of the emphysema, the patient was immediately hospitalised in the Maxillofacial Surgery Unit and was prescribed intravenous antibiotics because of the high risk of infection associated with the access of large amounts of air and water to soft tissue during a dental procedure. Indeed, dental compressed air, and not sterile water, contains Legionella and Pseudomonas, rendering antibiotic therapy and microbiological monitoring even more critical [6-9].

The patient was discharged 4 days later.

\section{Discussion}

Turnbull, in 1900, was the first to describe subcutaneous emphysema and pneumomediastinum developing after dental treatment, when a musician blew a bugle immediately after tooth extraction [3]. Heyman and Babayof reviewed 75 cases of emphysema developing after dental treatment from 1960

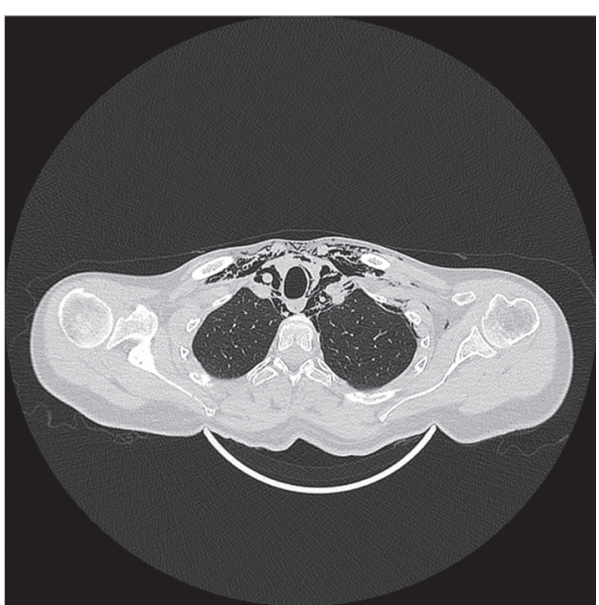

FIgURE 3: Computed tomographic axial view of the emphysema in the upper thorax, splaying the vascular bundle and running posterior to the clavicles with widening of the pectoral muscles.

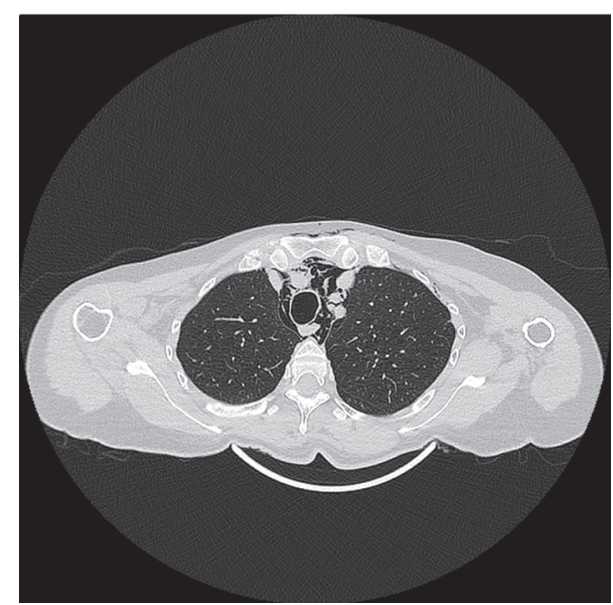

FIgURE 4: Computed tomographic axial view of the emphysema descending to the mediastinum, where it is evident mainly in the anterior region of perivascular adiposity and surrounding the trachea and oesophagus posteriorly.

to 1993 [10], and Arai et al. presented another 47 cases from 1994 to 2008 [5].

A variety of procedures can cause subcutaneous emphysema and pneumomediastinum, including injury, head and neck surgery, mechanical ventilation, and invasive procedures such as bronchoscopy.

A few cases have been observed during dental procedures, principally third molar extraction using an air turbine hand piece $[1,2]$. Some cases have been associated with the use of a dental laser, including $\mathrm{CO}_{2}, \mathrm{Nd}$ :YAG, and Er:YAG lasers. Fewer cases have been described after restorative or periodontal treatment that required no mucosal incision using peroxide hydrogen or sodium hypochlorite irrigants [5].

Swelling, dysphagia, chest pain, and crepitus are common signs and symptoms of emphysema and may develop immediately or within a few hours or days of the triggering procedure $[1,11]$. Features suggestive of pneumomediastinum are 
dyspnoea with a brassy voice, chest or back pain, or the Hamman sign $[5,12]$. The differential diagnosis of emphysematous complaints includes allergic reactions, haematoma, cellulitis, and angioedema [13]. When the diagnosis is difficult, the best option is empirical treatment as for an anaphylactic reaction until a definitive diagnosis is possible [7]. Emphysema is sometimes detected the day after a procedure [14].

Most patients who develop emphysema after dental procedures exhibit local symptoms that are benign and self-limiting in the clinic. Complications include the need for tracheostomy or thoracic drainage, mediastinitis, an air embolism [2, $7,11,15,16]$, pneumoperitoneum, pneumopericardium [17], and necrotising fasciitis [18]. Therefore, emphysema must be distinguished from gasses released by necrotising fasciitis with the help of serial CT imaging when necessary [7]. CT is the most useful imaging technique, affording excellent detail [5].

Although infection is not usually observed in subcutaneous emphysema, this condition has developed in some cases. The use of a prophylactic antibiotic therapy is recommended because the introduction of air, and not sterile water [9], and the migration of oral cavity microorganisms to the mediastinum [19] could have serious effects on the patient's health. For these reasons, simple bed rest with antibiotics has always been the therapy of choice [20,21].

However, there have been reports of death due to complications such as mediastinitis, pneumothorax, cardiac tamponade, cardiac failure, and air embolism [21, 22].

\section{Conclusion}

Our case is unusual in terms of the extent of emphysema noted and the simple dental procedure that triggered the problem. We present this case to emphasise that no matter how simple the planned procedure is, something can always go catastrophically wrong.

\section{Disclosure}

The English in this document has been checked by at least two professional editors, both native English speakers. For a certificate, please see http://www.textcheck.com/certificate/ u8012n.

\section{Conflicts of Interest}

The authors declare that there are no conflicts of interest regarding the publication of this paper.

\section{References}

[1] S. Yang, T. Chiu, T. Lin, and H. Chan, "Subcutaneous emphysema and pneumomediastinum secondary to dental extraction: a case report and literature review," The Kaohsiung Journal of Medical Sciences, vol. 22, no. 12, pp. 641-645, 2006.

[2] W. S. McKenzie and M. Rosenberg, "Iatrogenic subcutaneous emphysema of dental and surgical origin: a literature review," Journal of Oral and Maxillofacial Surgery, vol. 67, no. 6, pp. 12651268, 2009.
[3] A. Turnbull, "A remarkable coincidence in dental surgery," British Medical Journal, vol. 1, no. 2053, p. 1131, 1900.

[4] M. G. Maxwell, K. M. Thompson, and M. S. Hedges, "Airway compromise after dental extraction," Journal of Emergency Medicine, vol. 41, no. 2, pp. e39-e41, 2011.

[5] I. Arai, T. Aoki, H. Yamazaki, Y. Ota, and A. Kaneko, "Pneumomediastinum and subcutaneous emphysema after dental extraction detected incidentally by regular medical checkup: a case report," Oral Surgery, Oral Medicine, Oral Pathology, Oral Radiology and Endodontology, vol. 107, no. 4, pp. e33-e38, 2009.

[6] A. Ali, D. R. Cunliffe, and S. R. Watt-Smith, "Surgical emphysema and pneumomediastinurn complicating dental extraction," British Dental Journal, vol. 188, no. 11, pp. 589-590, 2000.

[7] G. K. An, B. Zats, and M. Kunin, "Orbital, mediastinal, and cervicofacial subcutaneous emphysema after endodontic retreatment of a mandibular premolar: a case report," Journal of Endodontics, vol. 40, no. 6, pp. 880-883, 2014.

[8] I. Döngel, M. Bayram, I. Ö. Uysal, and G. S. Sunam, "Subcutaneous emphysema and pneumomediastinum complicating a dental procedure," Ulusal Travma ve Acil Cerrahi Dergisi, vol. 18 , no. 4, pp. 361-363, 2012.

[9] B. Bilecenoglu, M. Onul, O. T. Altay, and B. U. Yakul, “Cervicofacial emphysema after dental treatment with emphasis on the anatomy of the cervical fascia," Journal of Craniofacial Surgery, vol. 23, no. 6, pp. e544-e548, 2012.

[10] S. N. Heyman and I. Babayof, "Emphysematous complications in dentistry, 1960-1993: an illustrative case and review of the literature," Quintessence International, vol. 26, no. 8, pp. 535543, 1995.

[11] Y. Kim, M.-R. Kim, and S.-J. Kim, "Iatrogenic pneumomediastinum with extensive subcutaneous emphysema after endodontic treatment: report of 2 cases," Oral Surgery, Oral Medicine, Oral Pathology, Oral Radiology and Endodontology, vol. 109, no. 2, pp. e114-e119, 2010.

[12] L. Hamman, "Spontaneous mediastinal emphysema," Bull Johns Hopkins Hosp., vol. 54, pp. 46-56, 1961.

[13] M. A. Aslaner, G. N. Kasap, C. Demir, M. Akkaş, and N. M. Aksu, "Occurrence of pneumomediastinum due to dental procedures," American Journal of Emergency Medicine, vol. 33, no. 1, pp. 125.e1-125.e3, 2015.

[14] A. Yoshimoto, Y. Mitamura, H. Nakamura, and M. Fujimura, "Acute dyspnea during dental extraction," Respiration, vol. 69, no. 4, pp. 369-371, 2002.

[15] K. J. Wright, G. D. Derkson, and K. H. Riding, "Tissue-space emphysema, tissue necrosis, and infection following use of compressed air during pulp therapy: case report," Pediatric Dentistry, vol. 13, no. 2, pp. 110-113, 1991.

[16] J. Sekine, A. Irie, H. Dotsu, and T. Inokuchi, "Bilateral pneumothorax with extensive subcutaneous emphysema manifested during third molar surgery: A case report," International Journal of Oral and Maxillofacial Surgery, vol. 29, no. 5, pp. 355-357, 2000.

[17] C. M. Sandler, H. I. Libshitz, and G. Marks, "Pneumoperitoneum, pneumomediastinum and pneumopericardium following dental extraction," Radiology, vol. 115, no. 3, pp. 539-540, 1975.

[18] S. C. Karras and J. J. Sexton, "Cervicofacial and mediastinal emphysema as the result of a dental procedure," Journal of Emergency Medicine, vol. 14, no. 1, pp. 9-13, 1996.

[19] J. B. Reznick and W. C. Ardary, "Cervicofacial subcutaneous air emphysema after dental extraction," The Journal of the American Dental Association, vol. 120, no. 4, pp. 417-419, 1990. 
[20] I. Horowitz, A. Hirshberg, and A. Freedman, "Pneumomediastinum and subcutaneous emphysema following surgical extraction of mandibular third molars: three case reports," Oral Surgery, Oral Medicine, Oral Pathology, vol. 63, no. 1, pp. 25-28, 1987.

[21] S. B. Aragon, M. Franklin Dolwick, and S. Buckley, "Pneumomediastinum and subcutaneous cervical emphysema during third molar extraction under general anesthesia," Journal of Oral and Maxillofacial Surgery, vol. 44, no. 2, pp. 141-144, 1986.

[22] J. W. Goodnight, J. A. Sercarz, and M. B. Wang, "Cervical and mediastinal emphysema secondary to third molar extraction," Head and Neck, vol. 16, no. 3, pp. 287-290, 1994. 


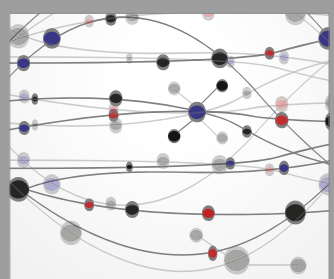

The Scientific World Journal
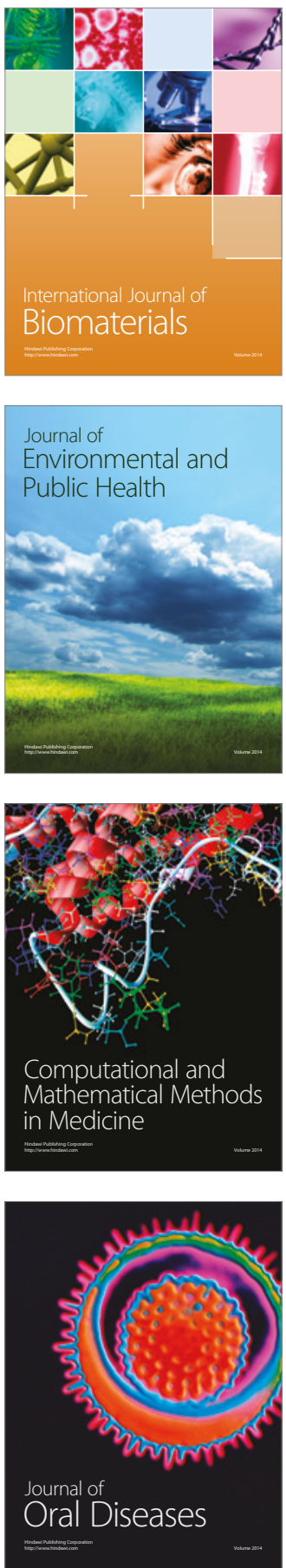
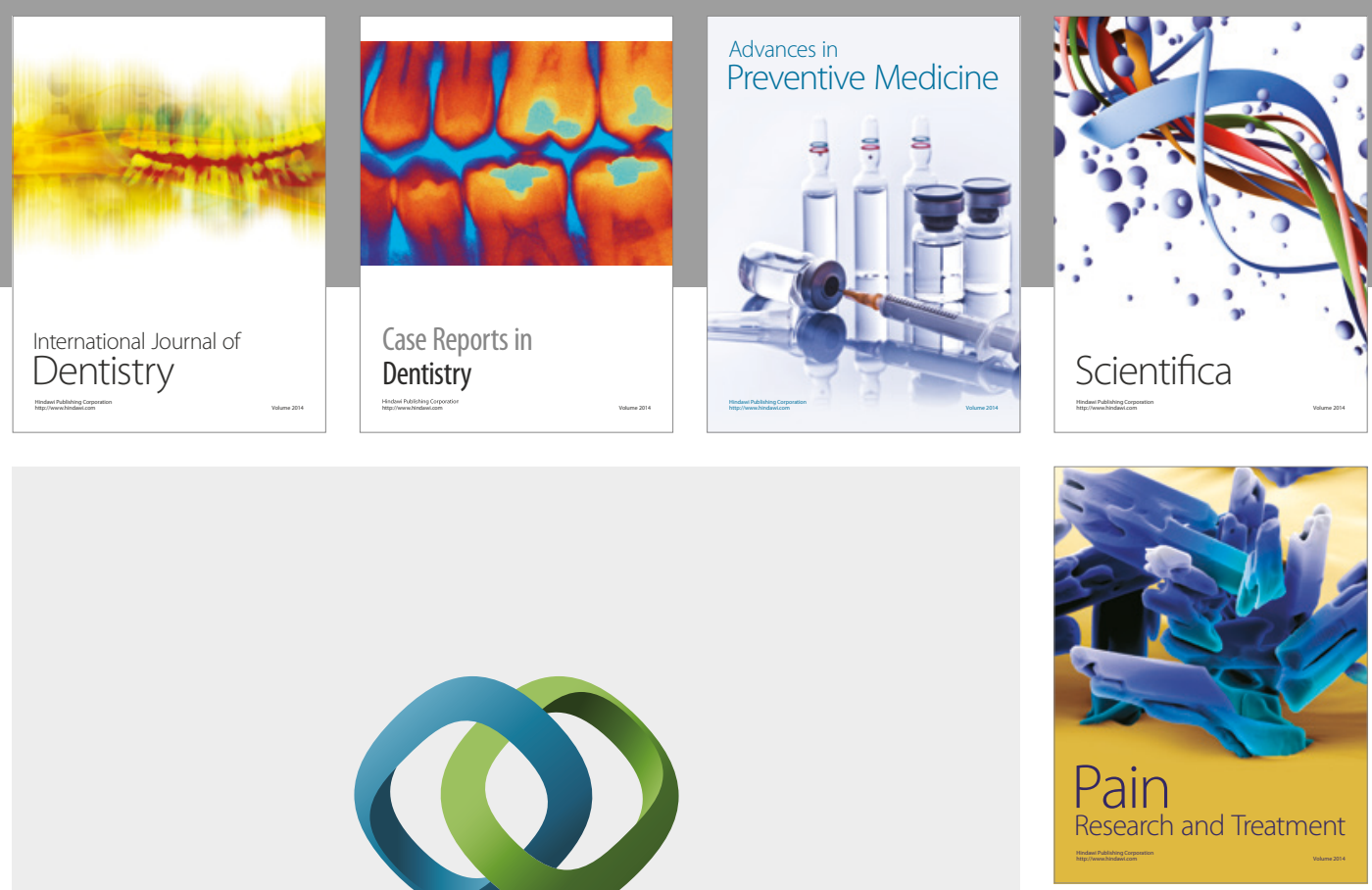

\section{Hindawi}

Submit your manuscripts at

https://www.hindawi.com
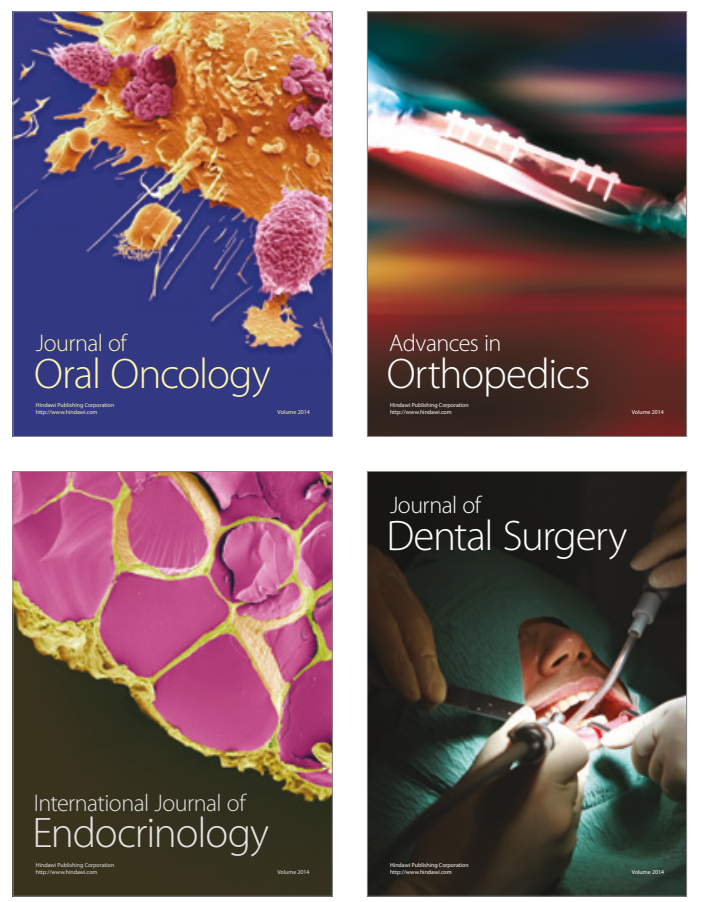
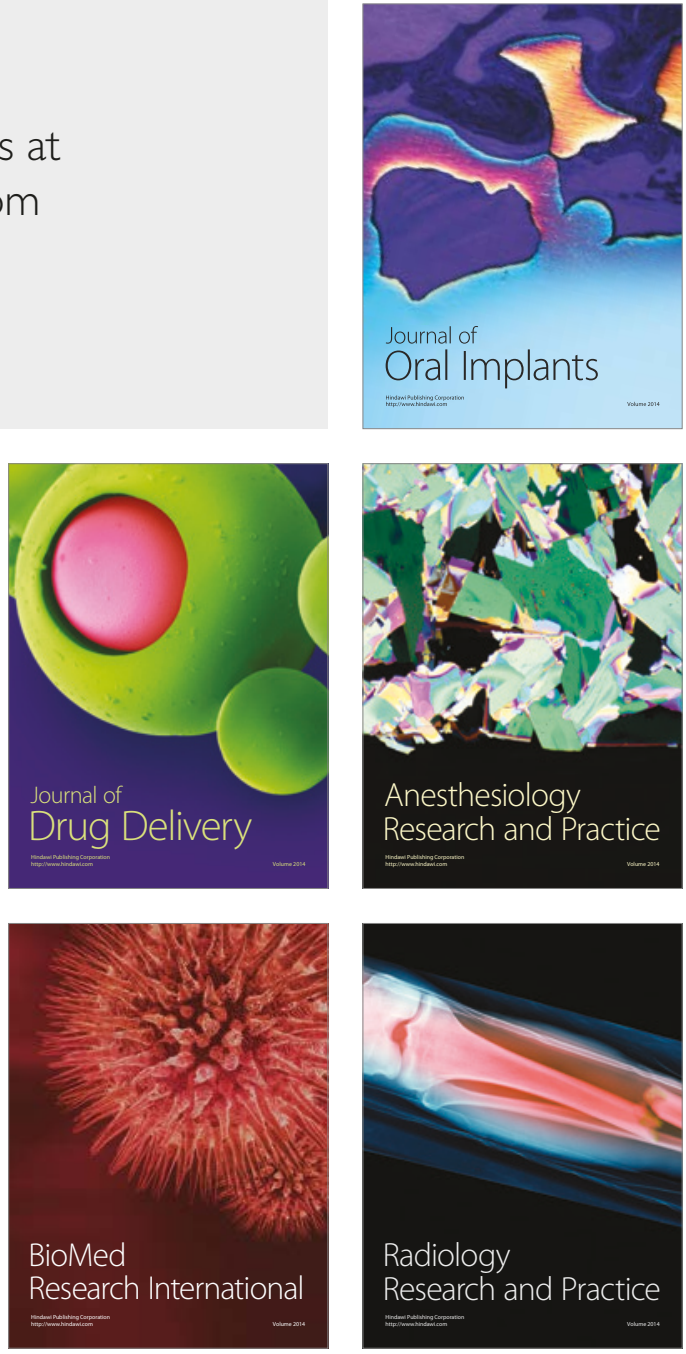